\title{
TOTAL MANAGEMENT: A CASE OF TRIBHUVAN UNIVERSITY
}

\author{
Arun K. Thakur*
}

\begin{abstract}
Total management refers to managing all elements/components and resources of the organization through analyzing the environmental situations and carrying out SWOT analysis so that the system of smooth operation can be ensured to accomplish the organizational goals. This article has analyzed the problems of T.U. under three components (i.e. teachers, staffs and students) with reference to the allocated resources (i.e. human, financial, physical and informational). Three major problems were identified separately through factor analysis which covers more than $80 \%$ of the problems related to each component and resources. The study shows that there are three major causes of all the problems in T.U. They are: Firstly, the appointment of executives, teachers and staffs is not done on the basis of senerioty and quality and placement of right kind of manpower are not made on the basis of the requirement of the job to be performed in efficient and effective manner. The second major cause is lack of commitment of employees towards their job (i.e. lack of dedication, devotion, determination and discipline). The third major cause is the dissatisfaction of employee in terms of salary, incentives, reward, and punishment.
\end{abstract}

Key Words: total management, total quality management, SWOT analysis, factor analysis, management by objective.

\section{INTRODUCTION}

This is the age of organization we are born in organization, attend education in organization and spend our productive life working in the organizations (Agrawal, 2013). Therefore, it is our responsibility to protect organizations in which we are involved and we need to utilize organizational resources in an efficient manner. Tribhuvan University (T.U.) is the biggest academic organization of Nepal in which we work and it is very important for us.

T.U. is the first university established in 1959 A.D. as a national level higher education organization in Nepal. It currently has 38 Central Departments, four research centers, and 60 constituent campuses located in different parts of the country. It runs educational programs under four Dr. Thakur is Reader in Management at Central Department of Management, T.U., Kirtipur,
Nepal 
Faculties and five human resource institutes with the aims of producing skilled manpower essential for the overall development of our country. T.U. has 15196 people working as teacher and staffs (TU Today, 201314).

The management of any organization relies on the effective coordination of their human, financial, physical, and informational resources. The meaning of management has been changing these days. According to Taylor (1911), "management is knowing exactly what you want people to do and then seeing that they do it in the best and cheapest way." But, Robbins and Decenzo (2013) view management as "the process of getting things done effectively and efficiently through and with other people." If we see these two definitions of different periods it is found that previously, management was taken as achieving goals in best and cheapest way but now it is taken as a process of planning, organizing, staffing, leading, and controlling the activities of an organization for achieving goals in effective and efficient manner. This gap in definitions of two periods is likely to be the difference between MANAGEMENT and TOTAL MANAGEMENT. TU needs to incorporate the features of Total Management. At present, in the context of globalization, there is a need of TOTAL QUALITY MANAGEMENT in organizations.

Total management is a concept which helps to bridge the gap of the two extremes of management mentioned above. This is a situational approach to management used mostly in the context of under developed countries like Nepal. It is a process/system through which are; (1) Identify and determine situational variables/elements/stakeholders, (2) Identify/diagnose the problems of each element, (3) Determine and rank the major three factors that are affecting or influencing each element or subsystems, (4) Develop the alternative solutions to the problem related to major factors through Strengths, Weaknesses, Opportunities and Threats (SWOT) analysis, (5) Select the best alternative to solve problems, and (6) Implement it to manage the elements/components. Here, opportunities are to be capitalized and the degrees of threats are to be managed to resist the negative implications for the implementation of plan. Control functions of management (pre-control, concurrent control and post-control) are required to be activated sincerely at every part of the system. This has to be followed to manage all the subsystems or elements and resources side by side to run and conduct the whole system of organization smoothly at the present context of our country, Nepal.

Every problem is the outcome of a situation. Situation is the outcome of internal and external environment to the organization. It is the duty of the manager to search about strengths and weaknesses from internal environment and opportunities and threats from external environment of the organization. The person who can do this work efficiently and effectively through optimum utilization of the resources available to the organization will be a good 
manager of total management. Therefore, total management is a systematic process of doing management functions identifying the situational variables to handle the specific situations efficiently and effectively for the welfare of beneficiaries/stakeholders.

\section{STATEMENT OF THE PROBLEM}

T.U., as an academic organization has human resources of 15,196 as teachers and staffs. The numbers of students enrolled under different constituent campuses are 2,73,349. It has a vast amount of physical resources. Financial resources and informational resources are also rich. However, the key issues regarding T.U. are;

(a) Are human resources efficiently and effectively utilized?

(b) Are students at the core of the problem of T.U.?

(c) What are the problems of T.U. regarding mobilization of financial resources?

(d) Are the informational resources sufficient and efficiently handled for the smooth operation of T.U.?

\section{OBJECTIVES OF THE STUDY}

The main objectives of this study are as follows:

(a) To diagnose the major problems of T.U. regarding human, physical, financial and informational resources.

(b) To identify the major three causes of the overall problems of T.U. through factor analysis.

(c) To suggest the way-outs to overcome the overall problems of T.U.

\section{RESEARCH METHODOLOGY}

This study is based on descriptive and analytical research design. To collect the information for the study, both primary and secondary sourcesof data were used. Primary information was collected through focus group discussions of teachers, staffs and students of constituent campuses of T.U., opinions were collected from high ranking bureaucrats of the Ministry of Finance and personal observations recorded during visits of different constituent campus of T.U. Secondary sources, used for the study are; bulletins, publications made by the Information Section of T.U. and Audit Reports of T.U. For the analysis and interpretation of the data, factor analysis was used as a statistical tool. Factor analysis is also known as three component analysis, where three major components/reasons or factors are selected among identified factors on the basis of highest weightage carried by each component. These three components have accumulated the weightage of more than 80 percent. It means, 80 percent of problem arises due to first three factors and rest of the problem arise due to other causes/factors. 


\section{LIMITATIONS OF THE STUDY}

(a) This study was confined to only constituent campuses. Affiliated campuses of the T.U. were not included.

(b) Since there are a number of factors responsible for the problems related to different components and resources of T.U., this study was confined to determine three major problems of each component of human resource and other resources on the basis of the factor analysis.

\section{RESULTS AND DISCUSSIONS}

An organization operates with the combination of four resources viz. human, financial, physical and informational. First of all, let's discuss about the problems of human resource of T.U. and a component of human resource is the teachers. There are 7,966 teachers, appointed at various levels viz. Instructor, Teaching Assistant, Lecturer, Reader and Professor (TU Today, 2013-14). About 50 percent of them are not permanent and they have been working for more than ten years. They have spent their productive life for T.U. but they are still in uncertainty about their future. This is the first major problem. Among the permanent teachers, about 50 percent are in their retiring age. They had been confined themselves in teaching the students of proficiency certificate level and this level has already been phased- out from T.U. Some of these teachers have not upgraded themselves to teach at the higher levels and they are simply a burden for the university. This is the second major problem. Thirdly, salary and incentives of teachers are not attractive and motivating that might affect in the commitment and performance of the employees. Other problems are also inherent in T.U. regarding teachers but the current article is looking only at these three major problems.

The second component of human resource is the staff of T.U. There are more than seven thousand people working as administrative, technical, and utility staff. The first two problems associated with the teachers discussed above are also true for the staff but the third problem which is specific to this particular group is that their academic qualifications and job specifications do not match. So, they are not in a position to discharge their responsibilities effectively and show their desired performance.

The third component that plays key role in TU is the students. There are 2,73,349 students studying in the 60 constituent campuses of T.U. Among them $10.19 \%$ are enrolled in technical institutes and rest of them are studying in law, management, humanities and education faculties (TU Today, 2013: 14). The first major problem lies with students is their academic qualifications at the entry level. Most of them do not seem to be eligible for the enrollment at higher level. Entrance examinations are 
taken for the sake of formality. Wrong selection creates problems in teaching-learning process, and it affects the timely completion of the courses prescribed for the study and students-teacher relationship. The second major problem associated with the students is the behavior of the students. The students of present time are in the transitional political period prevailing in the country. They are very much concerned about their rights but less worried about the responsibilities to be discharged and the code of conduct of the academic institutions. Another problem is that they demand class notes of the courses from teachers while in class for the study. Students are fully dependent on the teacher's notes. This makes them dull and the notes create obstacles to celebrate their creativity.

At present, the financial position of T.U. is not sound as it is heard and seen. The sources of the revenue are; rent from land and buildings of T.U., student's fees, and the grants provided by University Grant Commission (UGC) of Nepal. The rent of land is often not paid by the tenants and the T.U. management does not make adequate efforts towards the collection of such revenue strictly. Appropriate provisions have not been made in the procedures of determining rent for building or physical structures of T.U. It is heard that in some campuses, such types of revenues are not properly used. The revenue generated from students is getting low because of the decreasing number of students in the constituent campuses. At present, the government of Nepal is releasing funds to the universities only to pay the regular salaries of the permanent teachers and staffs on the basis of the number of posts (darbandi) sanctioned by the Ministry of Finance. The comments made by the government of Nepal on T.U. are; lack of transparency about the number of posts sanctioned by the Ministry of Finance and number of appointments made in T.U., non-recovery of unsettled expenditures and advances taken in the name of executives and staffs, amounted to be more than a billion rupees (Audit Report, 2070). Therefore, the income of the university is getting low and organization is in crisis to meet the expenditures required to conduct the regular academic and administrative programs at the center and in different constituent campuses of the T.U.

The physical resources of T.U. are very rich in terms of the area of land located in expensive places. People have donated land to different constituent campuses situated at either important places of the region or the headquarters of the districts. These lands can be used for different purposes to generate revenue for TU. Unfortunately, the management of T.U. is unable to adequately utilize these land resources in a productive manner. In some places, land of T.U. has been captured by newly established universities in different regions of the country. Buildings of many campuses have been constructed through donations given by people, 
neighboring countries and soft loans provided by international agencies but many of these structures are not in a position to be used by campuses. Some of them are abandoned. Their bricks and wood materials have already been stolen. Most of the campuses have crisis of fund for repair and maintenance of their physical structures.

Informational resources are also weak in T.U. Detail Information regarding revenue, expenditures, physical properties, teachers, staffs and students are not adequately maintained or their records are not up to date. Recording and filling system are also not proper. This situation is creating problems to the planning division to prepare realistic strategic plan of each component and resources and smooth operation of T.U.

Sister organizations of the various political parties are active and they often fight to get their share in the appointment of various posts. They generally forget or avoid the principles of right person at the right post. Right person can be determined on the basis of qualifications, experiences and skills required to perform their assigned job and to take decisions. These are ignored sometimes. Age factor is also important because it determines their level of needs, which leads to behavior of people. It is found that young people are mostly economically motivated, less experienced and highly energetic to meet the physiological and safety needs whereas middle aged groups have moderate degree of experience and they are trying to fulfill their social and esteem needs. Old age groups are highly experienced and trying to be self-actualized. Which type and group of manpower is suitable at which post are not taken into consideration while appointing in the various posts of TU. As a result, their performance is questioned against health, reputation and betterment of the university.

Commitment is the outcome of motivation, quality of human resource and ownership. Here at TU, motivational tools are mostly not brought into practice, promotions are often questioned and commitment among the people working at the university is an issue.

The salary of teachers and staffs given by the university is very low even to meet the expenditures of their basic needs. The salary is hardly enough to pay for food and rent. It is not enough to meet the expenditure of education for their children and health services required for their family. There is no provision of incentives to motivate the employee at work. As a result, the employees are involved in the private institutions at lower pay, getting exploited. They become dissatisfied and frustrated with their job and life.

This is the age of team management where specialized/expert people are taken to form teams. Inclusiveness is also required in the team to develop 
ownership and getting feedback in the organization. The most important factor of any organization is human resource factor. They are the leaders of any organization. All resources of the organizations are generated and used by them. Human resources of the organization are classified in three categories. They are at top level, middle and lower level. Their responsibilities are also different. In the context of T.U. top level includes professors working as Deans, Directors, Registrar, Rector and Vice-chancellor and some administrative heads who are involved in policy level planning of T.U. Middle level and lower level are involved in implementation of policy plan and programs and maintaining financial records and doing day to day administrative functions. To perform their duties or to discharge their responsibilities they need certain qualities in terms of their qualifications, age, experience, skills etc. The question arises about the recruitment and selection process of human resources required to meet the academic and administrative needs of the university for which T.U. service commission is responsible. T.U. service commission pleads that they have not participated in making decisions regarding number of people to be recruited or promoted and determining the criteria for recruitment and selection of teachers and staffs of different levels. Therefore, vacancy is not announced timely and needs of the institutions cannot be fulfilled.

\section{CONCLUSIONS}

The factor analysis of all major problems found under different components and resources of T.U. shows that there are three major factors responsible for all the problems mentioned above. They are; (1) Political intervention (2) Lack of commitment among the people to their job. They do not want to improve themselves to be up-to-date to meet the requirement of the job and (3) Dissatisfaction regarding incentives, career development opportunities of teachers and staffs working at different levels of the university system.

\section{SUGGESTIONS}

Management refers to managing people efficiently. Management of organization can be done through the coordination of its human, financial, physical and informational resources. If all these resources can be properly coordinated, utilized, motivated and mobilized through human resource working at different levels of management, the organization can function successfully and efficiently. Therefore, it is the responsibility of the management of T.U. to utilize their human assets for the betterment of the University and maintaining its pride.

To solve the problems of T.U. following recommendations and suggestions are made:

I. Political interventions should be immediately controlled to run the 
prorammes of TU smoothly.

II. Idle human resource can be engaged by including (+2) programs in the morning or evening shift in different campuses. As a result, employees of T.U. cannot be thought of burden and revenue of the university can also be enhanced.

III. T.U service commission is to be made autonomous in the real sense. It should be strict and responsible for the recruitment and selection of people through regular vacancies.

IV. Training and development programs should be conducted regularly to upgrade the quality of teachers and staffs.

V. A commission for appointment of executives should be formed. Defined process (like written examination or open deliberations/interview about problems, vision, plan and programs) should be followed to select the right kind of people as the executive heads.

VI. Management by objectives (or participatory approach of decision making) should be followed so that ownership can be developed and commitment can be gained from employees.

VII. The salary of employees should be made enough at least to maintain their standard of living, comparable to the SAARC countries and reward should be given on the basis of contributions made by employees in enhancing the image and pride of the university.

\section{WORKS CITED}

T.U. TODAY (2013-2014). Kirtipur: Information Section, T.U. Press.

Agrawal, G.R. (2013). Principals of Management in Nepal. Katmandu: MK Publisher and Distributors.

Decenzo, David A. and S.P. Robbins (1988). Personnel and Human Resource Management. New Delhi: Prentice-Hall.

Drucker, Peter F. (1954). The Practice of Management. New York: Harper and Brothers.

Fiedler, Fred and M.M. Chemers (1974). Leadership and Effective Management. Glerview: Illinois: Scott, Foresman.

George, Claude S. (1974). The History of Management thought. New Delhi: Prentice-Hall.

Robbins, S.P. (1999). Organizational behavior; Concepts, Controversies and Applications. New Delhi: Prentice-Hall. 